\title{
Reliability and validity of the international physical activity questionnaire in the Nord-Trøndelag health study (HUNT) population of men

\author{
Nanna Kurtze*1, Vegar Rangul ${ }^{2}$ and Bo-Egil Hustvedt ${ }^{3}$
}

Address: ${ }^{1}$ HUNT Research Centre, Faculty of Medicine, Department of Public Health and General Practice, Norwegian University of Science and Technology, Trondheim, Norway, ${ }^{2}$ Department of Health Science, Nord-Trøndelag University College, Levanger, Norway and ${ }^{3}$ Institute of Basic Medical Sciences, Department of Nutrition, University of Oslo, Norway

Email: Nanna Kurtze* - nanna.kurtze@sintef.no; Vegar Rangul - vegar.rangul@hint.no; Bo-Egil Hustvedt - b.e.hustvedt@medisin.uio.no

* Corresponding author

Published: 9 October 2008

BMC Medical Research Methodology 2008, 8:63 doi:10.1186/147/-2288-8-63

This article is available from: http://www.biomedcentral.com/I47/-2288/8/63

(c) 2008 Kurtze et al; licensee BioMed Central Ltd.

This is an Open Access article distributed under the terms of the Creative Commons Attribution License (http://creativecommons.org/licenses/by/2.0), which permits unrestricted use, distribution, and reproduction in any medium, provided the original work is properly cited.
Received: 28 April 2008

Accepted: 9 October 2008

\begin{abstract}
Background: There is no standardized method for the assessment of physical activity (PA). Therefore it is important to investigate the validity and comparability of different measures. The International Physical Activity Questionnaire (IPAQ) has been developed as an instrument for cross-national assessment of PA and has been validated in 12 countries. These instruments have acceptable measurement properties for monitoring population levels of PA among I8-65 yearold adults in diverse settings. However, there are some concerns that IPAQ may over-report PA.

The purpose of this study is to evaluate the reliability and validity of IPAQ, short version, last 7-days in the NordTrøndelag Health Study (HUNT) population of men.

Methods: The questionnaire was administered twice to a random sample of 108 men aged 20-39 and validity by comparing results with $\mathrm{VO}_{2 \max }$ and ActiReg, an instrument that measures PA and energy expenditure (EE). ActiReg discriminates between the body positions: stand, sit, bend forward and lie and also registers if there is motion or not in each of them or both.
\end{abstract}

Results: Our results for reliability of the IPAQ short version were good for vigorous and fair for moderate activities. Intraclass correlations ranged from a low of 0.30 for moderate activity hours, to a high of 0.80 for sitting hours. Concerning validity, our results suggest that total IPAQ vigorous PA was a moderately good measure of vigorous activity, having moderately strong, significant correlations with $\mathrm{VO}_{2 \max }, r=0.4 \mathrm{I}(\mathrm{p} \leq 0.0 \mathrm{I})$, but correlated not with metabolic equivalent (METs) values of 6 or more measured with ActiReg. Only total IPAQ walking was fair correlated with METs $\mathrm{I}-3$ and METs $3-6$, respectively $r=-0.27$ and $0.26(\mathrm{P} \leq 0.05)$. The index for IPAQ sitting hours per week was moderate correlated with METs values of $\mathrm{I}-3$ and negatively correlated with METs values of 3-6. Classification of PA in three levels (low, moderate and high) correlated also most strongly with $\mathrm{VO}_{2 \max }(0.3 \mathrm{I} \mathrm{p} \leq 0.0 \mathrm{I})$ and METs $3-6$ and METs I-3 from ActiReg $(r=0.32$ and $-0.3 \mathrm{I}, \mathrm{p} \leq 0.0 \mathrm{I}$ ). Classification of $\mathrm{BMI}$ in three levels (normal, overweight and obese) correlated most strongly negative with $\mathrm{VO}_{2 \max }(-0.42 \mathrm{p} \leq 0.0 \mathrm{I})$ and $\mathrm{MJ}$ from ActiReg $(r=0.3 \mathrm{I} \mathrm{p} \leq 0.0 \mathrm{I})$.

Conclusion: Our results indicate that IPAQ short version for men has acceptable reliability and criterion validity for vigorous activity and sitting. Walking has moderate reliability. Only the IPAQ for walking had a fair correlation with METs $6+$. The questions about moderate activity had fair reproducibility and correlated poorly with most comparison measures. 


\section{Background}

Questionnaires are typically used in epidemiologic studies to assess physical activity (PA) levels, but the absence of widely accepted standardized methods and the use of different PA measures hinders national and international comparisons. However, the International Physical Activity Questionnaire (IPAQ) has been developed as an instrument for cross-national assessment of PA and has now been validated in 12 countries [1]. These instruments have acceptable measurement properties for monitoring population levels of PA among 18-65 years old adults in diverse settings. Long and short versions of the IPAQ are available which can be administered by telephone interview or self-administration. Two reference periods can be investigated, either the "last 7 days or "usual week". Overreporting of PA, especially of time and intensity [2], may be a problem in self-reported assessments, and there are some concerns that IPAQ may share this tendency.

Validity and reliability of the IPAQ has been addressed in several studies. One study has addressed possible overreporting in IPAQ, using the short last 7 day, telephone interview (IPAQ-S7T) [3]. In the European Physical Activity Surveillance System (EUPASS) researchers have compared several PA measures, including IPAQ, in a time series in eight countries of the European Union, highlighting methodological implications of the IPAQ (computeraided telephone interviewing) [4]. In another study, Rütten et al. [5] concluded that more research is needed to further investigate and improve the quality of the IPAQ (telephone interviewing). A Chinese version of IPAQ (long and short version) appeared to have acceptable reliability and validity, compared to other PA instruments used in various large epidemiological studies, although the short version underestimated the energy expenditure (EE) of total and moderate PA [6]. Hallal \& Victora [7] reported that the short version may systematically underestimate PA levels in Brazilian adults. A recent study suggested IPAQ is a reliable and valid measurement of total $\mathrm{PA}$ in a Chinese population, however the sub-components of total activity were less valid and reliable, (short, last 7 days) [8].

To our knowledge, when this study started, no one had yet criterion-validated IPAQ against physical fitness measures even though IPAQ was designed to measure particularly activities related to cardiorespiratory fitness [1]. However, Fogelholm [9] has later published a study comparing the IPAQ against $\mathrm{VO}_{2 \max }$ measured by submaximal ergometer cycle testing (self-administered IPAQ short format, last 7 days, S7S). A recent study by Ekelund et al. [10] also examined the short IPAQ, last 7 days version in Swedish adults, claiming their study to be the first to evaluate the absolute time spent in moderate and vigorous PA from the IPAQ questionnaire.
The purpose of this study is to evaluate the reliability and validity of the IPAQ short version questionnaire in a Norwegian sample of the Nord-Trøndelag Health Study (HUNT) population of men. It is unique in that we assess validity by directly comparing questionnaire results with direct measurements of PA and energy expenditure (EE) assessed with a position and motion sensor, ActiReg, as well as indirectly by comparing with $\mathrm{VO}_{2 \max }$.

\section{Methods \\ Subjects}

For this study 108 men, aged 20-39 were randomly selected from the population of Levanger and Verdal, two of the communities included in the Nord-Trøndelag Health Study (HUNT). They were selected with the goal to be representative of the current population of young adult men in the area. 250 were randomly selected by a statistical service and invited; 108 accepted. With the sample size of 100 , the study had an estimated $88 \%$ power to detect a correlation of 0.3 between the score from the IPAQ questionnaire and $\mathrm{VO}_{2 \max }$. The population of Nord-Trøndelag is stable with sex- and age distributions similar to those of Norway as a whole, but with somewhat lower levels of education and income compared to national averages.

An invitation letter was mailed with a pre-addressed, postage paid envelope, which was to be completed and returned; participation was voluntary. Height was measured without shoes with a wall-mounted tape measure, and weight with a laboratory scale (Heine Professional, 7800 ) at the test laboratory of Nord-Trøndelag University College. Body mass index (BMI) was computed as weight in kilograms divided by height in meters squared. We also recoded BMI in a categorical score, classified into three levels ("normal" $\left(<25 \mathrm{~kg} / \mathrm{m}^{2}\right)$, "overweight" (25-29.99) and "obese" $\left(\geq 30 \mathrm{~kg} / \mathrm{m}^{2}\right)$.

The study was approved by The Norwegian Data Inspectorate Board (IRB) and each subject gave his written informed consent prior to participation in the study. Further, the Regional Committee for Ethics in Medical Research recommended the protocol.

\section{Survey measures of IPAQ short version, self-administered last 7 days (IPAQ-S7S)}

PA was assessed using the IPAQ-S7S translated into Norwegian by The Norwegian Directorate of Health and Services. We used the instructions given in the IPAQ manual for reliability and validity, which is detailed elsewhere [1] http://www.ipaq.ki.se.

To sum up the single indicators to an overall indicator of PA-related EE (Metabolic equivalent, MET $\min ^{-1}$ ) is a major goal of the IPAQ instruments. We used the recommended, following MET estimates of IPAQ: Vigorous PA = 
8 METs, moderate $\mathrm{PA}=4$ METs, walking on average $=3.3$ METs. For calculating the overall METs PA, each category was multiplied with its special MET estimate value (we call it IPAQ METs). We also did some recoding: if someone said they "never" walked or walked "0" days per week, then hours per day and minutes per day were coded as "0".

We also used the recommended categorical score, three levels of PA (low, moderate and high) as proposed in IPAQ Scoring Protocol (short form). Low activity represented individuals who do not meet the criteria for moderate and vigorous intensity categories (< 599 MET-min/ week). Moderate activity represented moderate - or vigorous -intensity activities achieving a minimum of at least $600 \mathrm{Met}-\mathrm{min} /$ week. High activity represented achieving a minimum of a least 3000 Met-min/week.

Before the $\mathrm{VO}_{2 \max }$ test, participants completed the selfadministered IPAQ short version. This version consists of 7 questions addressing PA, over the last 7 days in all context of everyday life. Addressing days, hours and minutes per week in vigorous PA, moderate activity, walking and sitting during a weekday. For each intensity group we recoded a total IPAQ by computing an index of days, hours and minutes. These questions from IPAQ we also calculated METs and hours per week in vigorous and moderate activities, walking and sitting, as described by Craig et al. [1] and already mentioned.

\section{Reproducibility}

Reliability was evaluated by the asking each subject to complete the questionnaire one week after first taking it, using a test-retest design.

\section{Validity}

In the absence of a true "gold standard" and as PA is a multidimensional exposure, we evaluated validity by comparing the PA data from the self-reported IPAQ with several measures related to PA: $\mathrm{VO}_{2 \max }$ and five measures of PA assessed with ActiReg - Megajoule (MJ) per day, hours at metabolic equivalent (METs) $>6$, hours at METs 3-6, hours at METs 1-3 average per day and physical activity level (PAL), defined as total EE divided by basal metabolic rate (BMR) [11]. As many others studies, we used $\mathrm{VO}_{2 \max }[12,13]$ which reflects fitness, as an indicator of PA-related fitness or aerobic training. A correlation between $\mathrm{VO}_{2 \max }$ and PA assessed using the questionnaire would suggest that the questionnaire was measuring aspects of PA, such as aerobic training-related fitness level. The measures obtained from ActiReg reflect different aspects of PA, measured more directly.

We have used the first test of IPAQ in comparison against $\mathrm{VO}_{2 \max }$ and ActiReg, which means that the participants were not familiar with the questionnaire and they were not given a "training round".

\section{Testing for Maximal oxygen uptake $\left(\mathrm{VO}_{2 \max }\right)$}

For measuring $\mathrm{VO}_{2 \max }\left(\mathrm{ml} \cdot \mathrm{kg}^{-1} \cdot \mathrm{min}^{-1}\right)$ Metamax II (Cortex Biophysic GmbH, Leipzig, Germany), a metabolic analyzer was used (serial no. MII 63229 901). The instrument was used stationary at the physiological test laboratory at Nord-Trøndelag University College. It recorded and displayed data at $10 \mathrm{~s}$ averages which was transferred to a PC using the programme Cortex Metasoft. The Metamax II oxygen analysers has been examined in a study using the Douglas bag technique as the control method [14]. The instrument has built-in sensors for $\mathrm{O}_{2}, \mathrm{CO}_{2}$, a barometer and a thermometer which measure the flow of the breathed air by means of a turbine flow meter attached to the breathing mask or mouthpiece. The instrument was calibrated against ambient air and a commercial gas of known concentrations of $\mathrm{O}_{2}(16.00 \%)$ and $\mathrm{CO}_{2}(4.00 \%)$ in the morning before the start of each experiment. The concentration of $\mathrm{O}_{2}$ and $\mathrm{CO}_{2}$ of room air was read and the flow transducer was calibrated using a 3 -L high-precision calibration syringe (Calibration syringe $\mathrm{D}$, SensorMedics, Yorba Linda, CA) before testing a new subject.

The subjects were instructed not to eat or smoke at least 2 hours before the test. Water could be taken as needed at any time. No unusual physical activity efforts should have been performed at least 12 hours before testing, and subjects were to dress appropriately for exercise, especially with regard to footwear.

Before the $\mathrm{VO}_{2 \max }$ test the participants also signed a statement that they were healthy and fit for the $\mathrm{VO}_{2}$ max test on treadmill; all 108 participants declared themselves fit.

A maximal treadmill exercise test was performed to test $\mathrm{VO}_{2 \max }$ in accordance with recommendations [15]. The speed was increased gradually and the incline was steady at $5 \%$. Before the test, subjects had warmed up for $15 \mathrm{~min}$ at $5 \%$ gradient and individual speed. After the warm up the subjects prepared to start the test after 2-3 minutes break. The test started with 2 minutes of exercise intensity corresponding to approximately $60 \%$ of $\mathrm{VO}_{2 \max }$. This intensity was estimated during the warm up. After $2 \mathrm{~min}-$ utes the treadmill speed increased gradually during 1 minute to a level that brought the subject close to exhaustion in approximately 3-4 minutes. This workload should have been kept up for 3-5 minutes. We asked subjects to continue for 4 minutes. After 2 minutes the respiratory quotient (RQ) should be at least 1.00. If it was lower, the speed was increased, if the RQ was greater than 1.20 we had to reduce the speed. During the last 2 minutes the workload could not increase, but before that it's possible to increase the workload up to $10 \%$. During the test, RQ 
was estimated to control for satisfactory workload. When the $\mathrm{O}_{2}$ uptake showed no further increase or increased only slightly with a further increase in the treadmill speed and if the $R Q \geq 1.05$ the test was considered successful. Otherwise the run was continued until a levelling-off was seen or until exhaustion. A subject's $\mathrm{VO}_{2 \max }$ was taken as the median of the three successive highest $\mathrm{O}_{2}$ registrations.

\section{ActiReg for measurement of PA and EE}

In order to measure total EE, intensity of expenditure and time spent at various intensity level a relatively new instrument, ActiReg (PreMed AS, Oslo, Norway) was employed. ActiReg is an electromechanical device, which records the main body positions (stand, sit, bent forward and lie) together with motion of the trunk and/or one leg each second [16]. The position (tilt switches) and motion sensors are fixed to plastic brackets. During registration the subjects wear ActiReg in a belt and the sensors are connected to the box with thin cables. The brackets are attached by medical tape to the subject's chest (on sternum) and on the front of the right thigh approximately midway between the knee and the hip. The tilt switches are oriented so that they will be in the vertical position when the subject is standing.

A dedicated computer program (ActiCalc32) calculates EE and activity pattern from the collected information and calibration data [16]. The calculation model used by ActiCalc32 are based on the estimated cost of the actual body position and activity expressed as physical activity ratios (PAR) values (i.e. EE/RMR) combined with the number of position changes within each minute. PAR values used by the ActiCalc32 program during calculation of EE are published reference values for people with normal body weight [17]. The ActiReg system has been validated both against doubly labeled water and indirect calorimetry [16]. More details about the method are published elsewhere [16]. Thus each minute of the registration period is characterized according to its estimated PARvalue which can then be categorized into light, moderate and vigorous activity, such as METs 1-3, METs 3-6 and METs 6+.

After $\mathrm{VO}_{2 \max }$ testing participants were instructed how to wear ActiReg. In addition participants received an illustration with written instructions and a memory list about the use of ActiReg. They wore ActiReg for 7 consecutive days, all hours except while sleeping. For 15 people, fewer than 7 days were available, and they were excluded. We base results only on the days with measurements.

\section{Data analysis}

Statistical analyses were performed with SPSS, Inc., Chicago IL, version 15.0. Sample Power 2 was used to esti- mate the required sample size. To evaluate reliability, we calculated single measure intraclass correlation coefficients (ICC). A 95\% confidence interval (CI) was used to describe the variety/difference in the ICCs. To assess validity, we used Spearman correlation coefficients to measure the association of the questionnaire responses with $\mathrm{VO}_{2 \max }$ and ActiReg results. We also used Pearson correlation coefficients for comparison. We used ordinary least squares regression to assess and to adjust for possible covariates, but present results only from the Spearman correlation analyses since our results and conclusions were similar with other methods. Agreement between selfreported time spent in total IPAQ moderate and total IPAQ vigorous PA and measured time spent at the same intensity level by ActiReg was assessed with an BlandAlman technique [18]. We plotted the difference between the criterion-measured (by ActiReg) time spent in METs 3-6 and METs 6+ and self-reported total IPAQ moderate and total IPAQ vigorous PA against the criterion.

\section{Results}

As shown in Table 1 , the mean age of study subjects $(\mathrm{N}=$ 108 ) is 32.4 years and the means for weight, height and BMI are $85.5 \mathrm{~kg}, 180.2 \mathrm{~cm}$ and 26.3, respectively. Sixteen in the group who were 20-29 years of age and 45 in the group who were 30-39 years of age were classified as preobese (BMI 25.0-29.9), based on WHO's classification of $\mathrm{BMI}$; four and nine in each age group, were in Obesity class 1 (BMI 30.0-34.9).

Maximal oxygen uptakes were generally comparable to age-specific "normal" values [19], although the age-specific averages for men in this study were slightly higher. Ten in the group 20-29 years of age, and eight in the group 30-39 years of age had a somewhat low oxygen consumption, whereas four and twelve, respectively, had a high oxygen consumption in relation to classification of $\mathrm{VO}_{2 \max }[20]$,

Table 2 presents means and standard deviations of selected measures of physical activity and fitness for subjects in this study. The mean (standard deviation) $\mathrm{VO}_{2 \max }$ was 45.99 (6.24) and the mean (standard deviation) daily EE was about $12.7 \mathrm{MJ}(1.82)$.

\section{Questionnaire Reliability}

Table 3 gives ICC for the IPAQ questionnaires $(\mathrm{N}=108)$. Correlations ranged from a low of 0.30 for moderate activity hours, to a high of 0.80 for sitting hours.

\section{Validity}

Associations with ActiReg and $\mathrm{VO}_{2 \max }$

As can be seen in Table $4, \mathrm{VO}_{2 \max }$ which is sometimes referred to as a criterion measure of fitness, tended to increase as the hours with vigorous activity increased, up 
Table I: Physical characteristics, classification of BMI, $\mathrm{VO}_{2 \max }\left(\mathrm{ml}^{1} \mathrm{~kg}^{-1} \cdot \mathrm{min}^{-1}\right)$ and normal values of maximal oxygen uptake at the age of 20-39 and in the validation study

\begin{tabular}{|c|c|c|c|c|c|c|c|c|}
\hline \multicolumn{9}{|c|}{ Physical characteristics of subjects $20-39$ year $(N=108)$} \\
\hline & \multicolumn{2}{|r|}{ Age $(y r)$} & \multicolumn{2}{|c|}{ Weight $(\mathrm{kg})$} & \multicolumn{2}{|c|}{ Height (cm) } & \multicolumn{2}{|c|}{ BMI } \\
\hline & Mean & SD & Mean & SD & Mean & SD & Mean & SD \\
\hline Male & 32.4 & 5.24 & 85.5 & 12.20 & 180.2 & 7.88 & 26.3 & 3.16 \\
\hline \multicolumn{9}{|c|}{ Classification of BMI among subjects } \\
\hline Age, yr & $<18.50$ & $18.50-24.99$ & $25.00-29.99$ & $30.00-34.9$ & & & & \\
\hline $20-29$ & I & 10 & 16 & 4 & & & & \\
\hline $30-39$ & & 23 & 45 & 9 & & & & \\
\hline \multicolumn{9}{|c|}{ Subjects characteristics of $\mathrm{VO}_{2 \max }\left(\mathrm{ml} \cdot \mathrm{kg}^{-1} \cdot \mathrm{min}^{-1}\right)$} \\
\hline Age, $y r(N)$ & Low $(N)$ & Somewhat low $(\mathrm{N})$ & Average $(\mathrm{N})$ & High (N) & Very high $(\mathrm{N})$ & & & \\
\hline $20-29(31)$ & $38(3)$ & $39-43(10)$ & $44-51(13)$ & $52-56(4)$ & $57(1)$ & & & \\
\hline $30-39(77)$ & $34(2)$ & $35-39(8)$ & $40-47(40)$ & $48-5 \mid(\mid 2)$ & $52(15)$ & & & \\
\hline \multicolumn{9}{|c|}{ Normal values of maximal oxygen uptake, age of $20-39$ and in the validation study } \\
\hline & Normal values & & & ation study & & & & \\
\hline Age, yr, men & Mean & SD & Age, yr, men & Mean & SD & & & \\
\hline $20-29\left(\mathrm{ml} \cdot \mathrm{kg}^{-1} \cdot \mathrm{min}^{-1}\right)$ & 43 & 7.2 & $20-29\left(\mathrm{ml}^{\prime} \mathrm{kg}^{-1} \cdot \mathrm{min}^{-1}\right)$ & 45.8 & 6.39 & & & \\
\hline METs & 12 & & METs & 12.7 & & & & \\
\hline 30-39 $\left(\mathrm{ml} \cdot \mathrm{kg}^{-1} \cdot \mathrm{min}^{-1}\right)$ & 42 & 7.0 & 30-39 $\left(\mathrm{ml} \cdot \mathrm{kg}^{-1} \cdot \mathrm{min}^{-1}\right)$ & 46.1 & 6.22 & & & \\
\hline METs & 12 & & METs & 12.7 & & & & \\
\hline
\end{tabular}

Values are expressed as mean and standard deviation (SD). MET indicate metabolic equivalent $3.5 \mathrm{ml} \cdot \mathrm{kg}^{-1} \cdot \mathrm{min}^{-1}$.

to 4-6 hours per week. However, the trends were not monotonic, possibly reflecting the small number of subjects in some categories. However, those with 4-6 hours of vigorous PA had the highest mean of $\mathrm{VO}_{2 \max }(49.2)$. When $\mathrm{VO}_{2 \max }$ data were categorized into 2 or 3 groups, there was a clear trend showing a higher activity levels with increased fitness level. However, the differences were not significant, due to the nature of the activity scores which have zero values. This leads to high SD scores. The trends for other measures are less consistent.

To further assess validity, we examined the correlation of the self-reported IPAQ responses with $\mathrm{VO}_{2 \max }$ and with selected measures from ActiReg. Spearman correlation coefficients are presented in Table 5 . For $\mathrm{VO}_{2 \max }$, the correlation was highest with the total vigorous PA $(\mathrm{r}=0.41 \mathrm{p}$ $\leq 0.01)$, vigorous hour PA per week $(0.40 \mathrm{p} \leq 0.01)$ and vigorous days $(0.36 \mathrm{p} \leq 0.01)$ and IPAQ Mets $(0.30 \mathrm{p} \leq$ $0.01)$. For $\mathrm{EE}(\mathrm{MJ})$, the correlations with the questionnaire responses were positive for IPAQ METs $(r=0.26, p \leq 0.05)$ and negative for sitting hours per week $(r=-0.25, p \leq$ $0.05)$. Sitting hours per week was also significantly negative with PAL $(\mathrm{r}=-0.35, \mathrm{p} \leq 0.01)$ as well as with METs $1-$ $3(\mathrm{r}=0.44, \mathrm{p} \leq 0.01)$ and METs $3-6(\mathrm{r}=-0.42, \mathrm{p} \leq 0.01)$.
The time spent in activities with METs values $6+$ based on ActiReg most strongly correlated with hours walking per week as measured with IPAQ $(r=0.23, \mathrm{p} \leq 0.05)$ and total walking correlated most strongly with METs 1-3, METs 36 and METs $6+($ respectively $\mathrm{r}=-0.27,0.26,0.24, \mathrm{p} \leq 0.05$ ) and most weakly with vigorous hours per day $(\mathrm{r}=0.05)$. IPAQ METs correlated most strongly with METs 3-6 and METs $1-3$ from ActiReg ( $\mathrm{r}=0.34$ and $-0.32, \mathrm{p} \leq 0.01)$. Classification of PA in three levels correlated also most strongly with $\mathrm{VO}_{2 \max }(0.31 \mathrm{p} \leq 0.01)$ and METs $3-6$ and METs $1-3$ from ActiReg ( $\mathrm{r}=0.32$ and $-0.31, \mathrm{p} \leq 0.01)$. Classification of BMI in three levels correlated most strongly negative with $\mathrm{VO}_{2 \max }(-0.42 \mathrm{p} \leq 0.01)$ and $\mathrm{MJ}$ from ActiReg $(\mathrm{r}=0.31 \mathrm{p} \leq 0.01)$.

\section{Discussion}

In this study of young adult men, we found evidence for good reliability with high correlations between the test retest for the IPAQ questionnaire for vigorous days, hours and sitting hours per day and moderate for walking days and hours. Reliability was further fair for moderate activity days and hours.

Concerning validity, our results suggest that total IPAQ vigorous PA, was a moderately good measure of vigorous activity, having moderately strong, significant correlations 
Table 2: Means and standard deviations for responses to physical activity questionnaire (IPAQ short version, last 7 days) and criterion measures

\begin{tabular}{|c|c|c|c|}
\hline Measures & $\mathrm{N}$ & Mean & SD \\
\hline Vigorous activity days/week & 107 & 1.78 & 1.80 \\
\hline Vigorous activity hours/day & 104 & 1.29 & 1.86 \\
\hline Moderate activity days/week & 106 & 2.18 & 2.04 \\
\hline Moderate activity hours/day & 93 & 1.27 & 1.67 \\
\hline Walking $10 \mathrm{~min}$. days/week & 105 & 3.55 & 2.71 \\
\hline Walking hours/day & 95 & 1.11 & 2.22 \\
\hline Sitting hours/day & 92 & 5.91 & 3.5 \\
\hline Total IPAQ METs min/week & 84 & 4157.07 & 6095.86 \\
\hline 3 PA categories & 84 & 2.12 & 0.75 \\
\hline BMI & 108 & 26.3 & 3.16 \\
\hline BMI 3 categories & 108 & 1.81 & 0.63 \\
\hline $\mathrm{VO}_{2 \max }\left(\mathrm{mL} \cdot \mathrm{kg}^{-1} \cdot \mathrm{min}^{-1}\right)$ & 108 & 45.99 & 6.24 \\
\hline \multicolumn{4}{|l|}{ ActiReg } \\
\hline EE $\left(M J^{\prime \prime}\right)$ & 93 & $12.7 \mid$ & 1.82 \\
\hline $\mathrm{PAL}^{2)}$ & 93 & 1.68 & 0.2 \\
\hline METsI-33) & 93 & 20.97 & 1.34 \\
\hline METs3-63) & 93 & 2.69 & 1.26 \\
\hline METs $6+3)$ & 93 & 0.27 & 0.26 \\
\hline
\end{tabular}

1) average $E E(M J)$ per day

2) $P A L=$ average physical activity level in 7 days

3) $\mathrm{MET}$ = average hours per day

3 PA categories = Classification of physical activity in three levels;

"low", "moderate" and "high"

BMI (Body Mass Index) 3 categories = Classification of BMI in three levels ; "normal" $\left(<25 \mathrm{~kg} / \mathrm{m}^{2}\right)$, "overweight" (25-29.99) and "obese" $\left(\geq 30 \mathrm{~kg} / \mathrm{m}^{2}\right)$

Table 3: Test re-test reliability based on intraclass correlation coefficients (ICC) for the IPAQ (short version, last 7 days) questions $(\mathrm{N}=108)$

\begin{tabular}{lcc}
\hline Questionnaire & \multicolumn{2}{c}{$\mathrm{N}=108$} \\
\cline { 2 - 3 } & ICC & $95 \% \mathrm{Cl}$ \\
\hline IPAQ & & \\
Vigorous activity (days per week) & $0.6 \mathrm{I}$ & $0.48-0.72$ \\
Vigorous activity (hours per day) & 0.62 & $0.47-0.73$ \\
Moderate activity (days per week) & 0.34 & $0.16-0.5 \mathrm{I}$ \\
Moderate activity (hours per day) & 0.3 & $0.09-0.49$ \\
Walking (days per week) & 0.56 & $0.4 \mathrm{I}-0.68$ \\
Walking (hours per day) & 0.42 & $0.23-0.59$ \\
Sitting (hours per day) & 0.8 & $0.70-0.87$
\end{tabular}

$I C C=$ Single measure intraclass correlation coefficient
Table 4: Distribution of criterion measures based on $\mathrm{VO}_{2 \max }$ and ActiReg by IPAQ (short version, last 7 days) questionnaire responses

\begin{tabular}{ccccc}
\hline \multicolumn{6}{c}{ Mean (SD) for Each Factor } \\
\hline Measures & $\mathrm{VO}_{2 \max }$ & METs I-32) & METs 3-62) & METs 6+2) \\
\hline \multicolumn{5}{c}{ Vigorous activity hours/week') } \\
\hline 1 & $43.2(4.5)$ & $20.96(1.50)$ & $2.67(1.4 I)$ & $0.24(0.28)$ \\
$2-3$ & $49.2(6.1)$ & $20.92(1.23)$ & $2.65(1.09)$ & $0.35(0.27)$ \\
$4-6$ & $49.2(5.5)$ & $21.21(1.00)$ & $2.51(1.05)$ & $0.27(0.19)$ \\
$6+$ & $48.4(6.9)$ & $20.73(1.33)$ & $3.02(1.27)$ & $0.26(0.29)$
\end{tabular}

Moderate activity hours/week')

\begin{tabular}{ccccc}
\hline I & $44.7(5.9)$ & $21.08(1.52)$ & $2.57(1.46)$ & $0.26(0.29)$ \\
$2-3$ & $48.3(5.6)$ & $21.25(1.00)$ & $2.40(0.88)$ & $0.27(0.21)$ \\
$4-6$ & $47.7(6.7)$ & $21.09(1.45)$ & $2.69(1.43)$ & $0.21(0.11)$ \\
$6+$ & $45.5(5.8)$ & $20.28(1.07)$ & $3.43(0.98)$ & $0.29(0.26)$
\end{tabular}

Walking days least $10 \mathrm{~min}$. hours/week ${ }^{1)}$

\begin{tabular}{ccccc}
\hline 1 & $45.2(6.4)$ & $21.29(1.32)$ & $2.40(1.22)$ & $0.21(0.18)$ \\
$2-3$ & $45.2(7.0)$ & $21.25(1.23)$ & $2.50(1.20)$ & $0.25(0.19)$ \\
$4-6$ & $48.4(6.9)$ & $20.59(1.31)$ & $2.87(1.14)$ & $0.55(0.38)$ \\
$6+$ & $47.6(5.4)$ & $20.25(1.31)$ & $3.48(1.39)$ & $0.28(0.17)$
\end{tabular}

Sitting hours/week')

\begin{tabular}{ccccc}
\hline 3 & $45.7(5.8)$ & $20.38(1.31)$ & $3.22(1.27)$ & $0.23(0.22)$ \\
$4-6$ & $46.1(6.3)$ & $20.80(1.38)$ & $2.88(1.32)$ & $0.27(0.23)$ \\
$7-12$ & $47.2(5.8)$ & $21.59(1.10)$ & $2.07(0.96)$ & $0.27(0.24)$ \\
$13+$ & $43.6(8.0)$ & $22.44(0.46)$ & $1.36(0.22)$ & $0.20(0.27)$ \\
\hline
\end{tabular}

1) see http://www.ipaq.ki.se for full text

2) $M E T s$ = average hours per day.

with $\mathrm{VO}_{2 \text { max }}$ but correlated weakly with METs values of 6 or more measured with ActiReg. Only the IPAQ for walking had a fair correlation with METs 6+. The IPAQ sitting hours per week was moderately correlated with METs values of 1-3 and negatively correlated with METs values of $3-6$.

\section{Reliability}

Our study provides useful information about the reproducibility of the IPAQ short version. The reliability ranged from good for sitting and vigorous PA, and moderate for walking, to fair for moderate activity. Brown et al. [21] assessed test-retest reliability of four PA measures used in population studies and one of them was the short IPAQ. They pointed out that the ICC was lowest for the moderate questions ( 0.16 to 0.44$)$. In our study we also have the lowest ICC for the moderate questions (0.16-0.51 and 0.09-0.49). Since the development of the IPAQ, the EUPASS and the WHO have used it for monitoring and 
Table 5: Spearman correlation coefficients for IPAQ (short version, last 7 days) with the $\mathrm{VO}_{2 \max }$ and ActiReg to assess criterion validity

\begin{tabular}{|c|c|c|c|c|c|c|}
\hline \multicolumn{7}{|c|}{ Variables } \\
\hline Measures & $\mathrm{VO}_{2 \max }$ & $\mathrm{EE}(\mathrm{MJ})^{\prime)}$ & $\left.P A L^{2}\right)$ & METs') I-3 & METs 3 ) 3-6 & METs $s^{3} 6+$ \\
\hline \multicolumn{7}{|c|}{ IPAQ short version (last 7 days) } \\
\hline Vigorous days/week & $0.36 * *$ & 0.07 & 0.08 & 0.01 & 0.03 & 0.09 \\
\hline Vigorous hours/day & $0.40 * *$ & 0.05 & 0.09 & -0.04 & 0.09 & 0.05 \\
\hline Total IPAQ vigorous & $0.4 I^{* *}$ & 0.05 & 0.08 & -0.02 & 0.08 & 0.07 \\
\hline Moderate days/week & 0.15 & 0.21 & 0.17 & -0.13 & 0.16 & 0.14 \\
\hline Moderate hours/day & 0.18 & 0.17 & 0.11 & -0.05 & 0.12 & 0.07 \\
\hline Total IPAQ moderate & 0.19 & 0.16 & 0.14 & -0.1 & 0.17 & 0.1 \\
\hline Walking days/week & 0.18 & 0.05 & 0.08 & -0.07 & 0.07 & 0.19 \\
\hline Walking hours/day & 0.14 & 0.17 & 0.2 & -0.17 & 0.17 & $0.23 *$ \\
\hline Total IPAQ walking & 0.14 & 0.16 & $0.23 *$ & $-0.27^{*}$ & $0.26 *$ & $0.24 *$ \\
\hline Total IPAQ sitting & 0.07 & $-0.25 *$ & $-0.35 * *$ & $0.44^{* *}$ & $-0.42 * *$ & 0.31 \\
\hline IPAQ Mets min/week & $0.30 * *$ & $0.26 *$ & $0.29 *$ & $-0.32 * *$ & $0.34 * *$ & 0.15 \\
\hline 3 PA categories & $0.31^{* *}$ & 0.19 & $0.24^{*}$ & $-0.31 * *$ & $0.32 * *$ & 0.16 \\
\hline BMI 3 categories & $-0.42 * *$ & $0.3 I^{* *}$ & 0.45 & -0.09 & 0.08 & -0.08 \\
\hline
\end{tabular}

$* \mathrm{p}<.05, * * \mathrm{p}<.01$.

1) average EE (MJ) per day

2) $\mathrm{PAL}=$ average physical activity level in 7 days

3) METs = average hours per day.

see http://www.ipaq.ki.se for full text

3 PA categories = classification of physical activity in three levels; "low" "moderate" and "high"

BMI 3 categories = Classification of BMI in three levels; "normal" (< 25 kg/m²), "overweight" (25-29.99) and "obese" ( $\geq 30$ kg/m²)

surveillance. However, some have raised concern that use of the IPAQ may be associated with over-reporting of PA. In one study, $75 \%$ of subjects reported less PA with the modified procedure than with the short IPAQ telephone survey [3]. Twenty three of the 50 individuals were found to have reported some amounts of PA with IPAQ (either walking, or vigorous or moderate PA) when they should have reported none. The authors discuss how the IPAQ protocol asks respondents to report average time per day in each intensity category. In this way if PA is reported for more than a day, the respondents may report an average time per day and could over-report the mean time per day, by reporting the day they were most active. Another study gives some indirect support to overestimation of habitual PA in obese [22]. In the EUPASS study [5] the test-retest reliability scores of the IPAQ (short version, last 7 days telephone interview, S7T), were rather low. They concluded that more research was needed to further investigate and improve the quality of IPAQ.

Our results for re-test reliability of the IPAQ short version were good for vigorous and fair for moderate activities. The reliability of the IPAQ S7T from eight participating
EU countries in general ranged from 0.3 and 0.5 , which appears to be rather low for reliability. In the Chinese version of IPAQ, the test-retest reliability was completed twice with a three-day interval among college students and validity by Caltrac accelerometer [6]. The short IPAQ had ICC above 0.7 for PA. They concluded that both the long and short version had acceptable reliability and validity, compared to other PA instruments. However, the short version, underestimated the EE of total and moderate PA.

The IPAQ was developed to overcome differences in PA measurement. However, the IPAQ is itself a new instrument, making it difficult to compare it with other, older questionnaires. Many other measurement studies focus mainly on leisure time PA (LTPA). The study of Rütten et al. [4] highlights some of the methodological innovations of the IPAQ instrument. One is that many measurements methods focus mainly on LTPA, while the IPAQ integrates several domains and not only PA at work. This methodological shift may explain some of the differences i.e. in overall scores for PA. 


\section{Validity}

IPAQ and $\mathrm{VO}_{2 \max }$

Assessment of criterion validity depends on the validation criteria. In our study $\mathrm{VO}_{2 \max }$ was chosen as the primary criterion. The results in this study are similar to those often obtained in the general population with correlation coefficients between PA and fitness typically 0.3-0.5 [23]. In a study that evaluated 10 commonly used PA questionnaires [24], the correlation of $\mathrm{VO}_{2 \max }$ was stronger with reported heavy activity than for light activity. Fogelholm et al. [9] validated IPAQ against fitness in men aged 2143 years. They found that a weekly frequency of vigorous PA showed positive association with fitness. Fogelholm found mostly similar characteristics of young men (aged 21-43) in their study as in ours (aged 20-39, Table 1). In our study total vigorous PA, hours per week and days were most strongly correlated (respectively $0.41,0.40$ and 0.36 , $\mathrm{r}=\mathrm{p} \leq 0.01$ ) with $\mathrm{VO}_{2 \max }$.

\section{IPAQ and ActiReg}

To evaluate validity further we also used several directly measured aspects of PA measures assessed with ActiReg, including EE, PAL and METs 1-3. METs 3-6 and METs 6+. METs values of 6 or more measured with ActiReg correlated not, except for total IPAQ walking and walking hours per week, which correlated fair with METs 6+. Sitting hours per week correlated moderately with METs values of $1-3(0.44)$ and negatively correlated with METs values of 3-6 (-0.42). Ekelund et al. [10] indicated moderate criterion validity of the IPAQ instrument and the MTI Actigraph (Manufacturing Technology Inc., formerly known as The Computer Science and Application, (CSA)) with correlation ranging from 0.16-0.35. Craig et al. obtained the same correlation in their study [1]. In the Chinese version of IPAQ [8] using an MTI accelerometer there was weak agreement between IPAQ and the total MTI - derived activity and sub-components. In our study there is an average underestimation of IPAQ (total moderate, vigorous and walking) with $-433 \mathrm{~min} /$ week, limits of agreement 1605 to - $2471 \mathrm{~min} /$ week compared to ActiReg calculated in a Bland Altman plot (plot not shown). We think that the main reason for the underestimation by IPAQ is due to the fact that the questionnaire only asks for time periods with duration of $10 \mathrm{~min}$ and more, while ActiReg register each minute of the day with sufficient PA. The Chinese short version of IPAQ [6] also underestimated EE of total and moderate PA. Also Hallal \& Victora [7] reported possible underestimation of PA levels.

\section{IPAQ and total time of PA expenditure}

The IPAQ especially focuses on investigation of total time of PA energy expenditure (MET $\mathrm{min}^{-1}$ ) as these PA indicators are associated with reduced cardiovascular diseases and mortality and therefore have been applied in public health recommendations [25]. Rütten et al. [4] compared IPAQ results with other European studies and PA in the IPAQ-S7T and Germany had the highest median of vigorous PA, $26 \mathrm{~min}^{-1}$. In our study we had a mean of 16.11 average minutes per day or 0.27 hours per day assessed with ActiReg and METs 6+. In the study of Ekelund et al. [10] total self-reported PA (MET-min day ${ }^{-1}$ ) was significantly correlated with average intensity of activity (counts $\left.\min ^{-1}\right)$ from accelerometry $(\mathrm{r}=0.34, \mathrm{p}<0.001)$. Further in our study IPAQ METs correlated most strongly with METs 3-6 and METs 1-3 measured with ActiReg $(r=0.34$ and -.032, $\mathrm{p} \leq 0.01)$ and $\mathrm{VO}_{2 \max }(\mathrm{r}=0.30, \mathrm{p} \leq 0.01)$ and more weakly with total EE (MJ) and PAL ( $\mathrm{r}=0.26$ and $0.29, \mathrm{p} \leq 0.05)$.

In our study the correlation between vigorous activity and $\mathrm{VO}_{2 \mathrm{max}}$ are quite good, but vigorous activity do not correlate wit ActiReg 6+. This stronger association with the measures of vigorous activity is consistent with the pattern found in comparisons using $\mathrm{VO}_{2 \max }$. The fair correlations with weekly hours of time spent at $>6$ METs measured with ActiReg and the weaker association with other measures as with EE and PAL is not surprising. PAL is primarily determined by time spent in activities with low and moderate intensities, and that high intensity activity has little impact on daily EE [26]. Probably this also is the answer to why our result of walking correlates much better with ActiReg than ActiReg and METs 6+. Our results suggest that IPAQ S7S was a better measure of intense PA, rather than EE. The study of criterion validity of IPAQ short version in Swedish adults [10] showed that self-reported time in PA was significantly different from time measured by accelerometry.

Strengths of our study are use of two objective validation measures, such as use of treadmill derived maximal oxygen uptake values and ActiReg measuring PA and EE during waking hours across a 7-day observation interval for validation, and a one-week test-retest repeatability design. Study strengths are also the random selection of study participants from a larger existing study population. Previous studies usually evaluating the validity of PA questionnaire often include selected samples of volunteers, also IPAQ itself [1]. The limitation is however, due to economic resources at that time, a study of only men and the low response-rate may affect the results because the likelihood of bias. The age ranges is also narrow, which limits the application of results to older men.

\section{Conclusion}

In conclusion, our results indicate that the IPAQ short version for men has acceptable test-retest reliability and criterion validity for vigorous activity and sitting. Walking has moderate reliability. Only the IPAQ for walking had a fair correlation with METs 6+. The IPAQ sitting hours per 
week was moderately correlated with METs values of 1-3 and negatively correlated with METs values of 3-6. The questions about moderate activity had fair reproducibility and correlated poorly with most comparison measures.

\section{Competing interests}

The authors declare that they have no competing interests.

\section{Authors' contributions}

NK was responsible for study design, manuscript preparation, data collection and statistical analysis. VG and B-EH were respectively responsible for $\mathrm{VO}_{2 \max }$ testing and ActiReg data. All authors have read and approved the final manuscript.

\section{Acknowledgements}

The Faculty of medicine, The Norwegian University of Science and Technology (NTNU) supported this study by a Post-doctoral Research Fellowship. The Nord-Trøndelag Health Study (HUNT Study) was collaboration between HUNT Research Centre, Verdal and Faculty of Medicine, NTNU, The National Institute of Public Health, The National Screening Service of Norway, Oslo and The Nord-Trøndelag County, Council. The $\mathrm{VO}_{2 \max }$ test was completed at the University College of Nord-Trøndelag. The author acknowledges the assistance of Professor, Dr. Dana Flanders, Emory University, Atlanta in analysis and interpretation of data.

\section{References}

I. Craig CL, Marshall AL, Sjostrom M, Bauman AE, Booth ML, Ainsworth BE, Pratt M, Ekelund U, Yngve A, Sallis JF, Oja P: International physical activity questionnaire: I2-country reliability and validity. Med Sci Sports Exerc 2003, 35:1381-95.

2. Montoye HJ, Kemper HC, Saris WH, Washburn RA: Measuring physical activity and energy expenditure. Champaign, Human Kinetics. Ref Type: Serial (Book, Monograph) 1996.

3. Rzewnicki R, Auweele Y Vanden, De Bourdeaudhuij I: Addressing overreporting on the International Physical Activity Questionnaire (IPAQ) telephone survey with a population sample. Public Health Nutr 2003, 6:299-305.

4. Rutten A, Ziemainz H, Schena F, Stahl T, Stiggelbout M, Auweele YV, et al.: Using different physical activity measurements in eight European countries. Results of the European Physical Activity Surveillance System (EUPASS) time series survey. Public Health Nutrition 2003, 6:37|-376.

5. Rutten A, Vuillemin A, Ooijendijk WT, Schena F, Sjostrom M, Stahl T, et al.: Physical activity monitoring in Europe. The European Physical Activity Surveillance System (EUPASS) approach and indicator testing. Public Health Nutrition 2003, 6:377-384.

6. $\mathrm{Qu} \mathrm{NN}$, Li KJ: [Study on the reliability and validity of international physical activity questionnaire (Chinese Vision, IPAQ)]. Zhonghua Liu Xing Bing Xue Za Zhi 2004, 25:265-268.

7. Hallal PC, Victora CG: Reliability and validity of the International Physical Activity Questionnaire (IPAQ). Letter to the Editor. Med Sci Sports Exerc 2004, 36:556.

8. Macfarlane DJ, Lee CC, Ho EY, Chan KL, Chan DT: Reliability and validity of the Chinese version of IPAQ (short, last 7 days). J Sci Med Sport 2007, 10:45-5I.

9. Fogelholm M, Malmberg J, Suni J, Santtila M, Kyrolainen H, Mantysaari M, et al.: International Physical Activity Questionnaire: Validity against fitness. Med Sci Sports Exerc 2006, 38:753-760.

10. Ekelund U, Sepp H, Brage S, Becker W, Jakes R, Hennings M, et al.: Criterion-related validity of the last 7-day, short form of the International Physical Activity Questionnaire in Swedish adults. Public Health Nutr 2006, 9:258-265.

II. Mifflin MD, St Jeor ST, Hill LA, Scott BJ, Daugherty SA, Koh YO: A new predictive equation for resting energy expenditure in healthy individuals. Am J Clin Nutr 1990, 5 I:24I-247.
12. Siconolfi SF, Lasater TM, Snow RC, Carleton RA: Self-reported physical activity compared with maximal oxygen uptake. Am J Epidemiol 1985, I 22: I01-105.

13. Singh PN, Fraser GE, Knutsen SF, Lindsted KD, Bennett HW: Validity of a physical activity questionnaire among African-American Seventh-day Adventists. Med Sci Sports Exerc 200I, 33:468-475.

14. Medbo Jl, Mamen A, Welde B, von Heimburg E, Stokke R: Examination of the Metamax I and II oxygen analysers during exercise studies in the laboratory. Scand J Clin Lab Invest 2002. 62:585-598

15. Åstrand P-O, Rodahl K, Dahl H, Strømme SB: Textbook of work physiology: Physiological bases of exercise, New York 4th edition. 2003.

16. Hustvedt BE, Christophersen A, Johnsen LR, Tomten H, McNeill G, Haggarty $P$, et al:: Description and validation of the ActiReg: a novel instrument to measure physical activity and energy expenditure. Br J Nutr 2004, 92:1001-1008.

17. Food and Agriculture Organization/World Health Organization/ United Nations University: Energy and Protein Requirements. In World Health Organization Technical Report Series no 734. 724 Geneva, WHO; 1985.

18. Bland JM, Altman DG: Statistical methods for assessing agreement between two methods of clinical measurement. Lancet 1986, I:307-310.

19. Fletcher GF, Balady GJ, Amsterdam EA, Chaitman B, Eckel R, Fleg J, et al.: Exercise standards for testing and training: a statement for healthcare professionals from the American Heart Association. Circulation 2001, 104: 1694-1740.

20. Wilmore J, Costill D: Physiology of sports and exercise 2nd edition. Champaign IL; 1999.

21. Brown WJ, Trost SG, Bauman A, Mummery K, Owen N: Test-retest reliability of four physical activity measures used in population surveys. Journal of Science and Medicine in Sport 2004, 7:205-2I5.

22. Tehard B, Saris WH, Astrup A, Martinez JA, Taylor MA, Barbe P, et al.: Comparison of two physical activity questionnaires in obese subjects: the NUGENOB study. Med Sci Sports Exerc 2005, 37:|1535-I54|.

23. Paffenbarger RS Jr, Blair SN, Lee IM, Hyde RT: Measurement of physical activity to assess health effects in free-living populations. Med Sci Sports Exerc 1993, 25:60-70.

24. Jacobs DR Jr, Ainsworth BE, Hartman TJ, Leon AS: A simultaneous evaluation of 10 commonly used physical activity questionnaires. Med Sci Sports Exerc 1993, 25:8I-9I.

25. Pate RR, Pratt M, Blair SN, Haskell WL, Macera CA, Bouchard C, et al.: Physical activity and public health. A recommendation from the Centers for Disease Control and Prevention and the American College of Sports Medicine. JAMA 1995, 273:402-407.

26. Westerterp KR, Plasqui G: Physical activity and human energy expenditure. Curr Opin Clin Nutr Metab Care 2004, 7:607-6I 3.

\section{Pre-publication history}

The pre-publication history for this paper can be accessed here:

http://www.biomedcentral.com/1471-2288/8/63/prepub 